\title{
Resenha: \\ As geografias do acaso cartografadas em Outras fronteiras, de Ana Mafalda Leite
}

Gustavo Henrique Rückert ${ }^{1}$

Pensar o trânsito contemporâneo entre os países que compõem a Comunidade Lusófona é pensar o deslocamento entre as fronteiras erigidas no contexto colonial e que buscaram fixar identidades a partir das relações no âmbito da colonização. É o que faz Ana Mafalda Leite em Outras fronteiras: fragmentos de narrativas (2017). Tendo nascido em Portugal, a autora cresceu e iniciou seus estudos em Moçambique, de onde retornou para atualmente ocupar o posto de docente de Literaturas Africanas na Universidade de Lisboa. Apesar de ser mais reconhecida pelo público brasileiro em seu trabalho como pesquisadora e ensaísta ${ }^{2}$, Ana Mafalda apresenta uma trajetória de mais de trinta anos de poesia $^{3}$. Outras fronteiras, publicada em 2017, é sua nona coletânea de poemas. É, porém, sua primeira obra poética publicada no Brasil.

O livro divide-se em quatro partes. A primeira, intitulada "como se a manhã do tempo despertasse", aborda as fronteiras do próprio sujeito lírico, enunciado em sua condição de deslocamento: "Saberei porventura os lugares de onde fala esta voz? Os enigmáticos espelhos de onde se olha?" (LEITE, 2017, p. 10). Já a segunda, "poemas de Moatize”, constrói-se a partir das recordações da infância em Moçambique: "abriram-se os portais e aqueles com quem sempre estive vão e vêm passam / atravessam a fronteira" (LEITE, 2017, p. 22). A terceira parte, homônima ao livro, aborda a perspectiva da escrita dos viajantes acerca das terras de Moçambique, unindo suas vozes à do sujeito lírico: "os caminhos são sempre outros, bocas línguas pombeiros sertanejos informantes / desaparecem nos caminhos" (LEITE, 2017, p. 41). Por fim, a última parte, "o índico em Marrakesh", reescreve os deslocamentos tomando como referência o Oceano Índico. A partir da perspectiva do hibridismo cultural, assinala-se a diferença por meio dos elementos das mais variadas paisagens entre ocidente e oriente: "devagar fomos chegando pelas ruas e múltiplas portas da cidade cor rosavelho / aromatizada de especiarias de incensos e véus inesperados" (LEITE, 2017, p. 58).

Em comum às quatro partes está o manifestar de um sujeito lírico em trânsito, como já anunciava a seção que abre a obra. Ao movimentar-se pelas fronteiras do antigo império, relativiza-as. Relativiza-as não simplesmente do ponto de vista físico, mas identitário dialogando assim com as fronteiras culturais erigidas no processo colonial. De acordo com Doreen Massey (2008), o espaço não pode ser considerado como algo estático tal qual o limitaram os estudos que o definiram em oposição funcional ao tempo. Para a geógrafa, o espaço está sempre em construção e caracteriza-se pela multiplicidade, uma vez que é produto de inter-relações. Nesse sentido, pensar o espaço é pensar na disputa de narrativas que procuram significá-lo e ressignificá-lo.

1 Doutor em Literaturas Portuguesa e Luso-Africanas (UFRGS). Professor Adjunto de Literaturas em Língua Portuguesa (UFVJM).

2 Destaco aqui as obras A Poética de José Craveirinha (1990), Oralidades \& Escritas nas Literaturas Africanas (1998) e Literaturas Africanas e Formulações Pós-Coloniais (2003).

3 Destaco aqui as obras Em sombra acesa (1984), Rosas da China (1999) e Livro das encantações (2005). 
Em Outras fronteiras, o sujeito lírico em trânsito insere sua voz em meio a essas disputas acerca dos espaços envolvendo o trajeto entre África e Europa. Dessa forma, cartografa o espaço outrora caracterizado pelo colonialismo português na contracorrente. Tomando como ponto inicial da construção de sentidos Moçambique - o local da infância assinalado pela referência metonímica a Moatize -, o deslocamento assume um sentido inverso à literatura de viagem colonial: da "colônia" aos "outros mundos". É no solo africano que a terra acaba e o mar começa. O sujeito detentor da voz, aquele que nomina o espaço e a alteridade, parte de África.

Essa poética de um deslocamento que parte de África, transgredindo as fronteiras do mundo colonial, é assinalada textualmente das mais variadas formas. Elenco, nesse sentido, as seguintes imagens do transitar, presentes no decorrer dos poemas: roda de insetos; feitiço de escrita; azul ultramarino; bola de tênis; rio Moatize; Máscara Kapoli; Máscara Kampini; Máscara Dzwirombo; geometrias do acaso; interstícios. Igualmente, elenco as fronteiras transgredidas por essas imagens: dia e noite; poeta e poesia; vida e morte; criadores e criaturas; homens e animais; chuva e queimada; água e terra; ocidente e oriente; poesia e cartografia; voz do eu e voz do outro; um lado e outro da quadra de tênis; as cores, os aromas e as texturas. As imagens assinaladas propõem a transgressão das mais diversas linhas divisórias que a compreensão humana impôs ao mundo para controlá-lo, tornando-se o próprio poema algo que escapa aos contornos e não pode ser apreendido em suas fronteiras. Em "Fronteiras, de que lado pergunto-me", o sujeito lírico questiona:

onde terá começado a fronteira do dia com a noite? a fronteira da água com a terra? a do azul com o lilás? porque tão dividido

o mundo em dois? no tratado de tordesilhas levou-se a ibéria ao novo mundo e mais tarde sentados em berlim muitos outros desenharam os mapas a compasso e esquadro

um continente não interiormente navegado diziam kurtz apontando o dedo ao acaso em caligrafias de cor ou a tinta da china um coração das trevas mapa cor de rosa a estilete gravado

nas mãos os mistérios arcos de décadas em bissectriz dançando a caneta em forma de bisel (LEITE, 2017, p. 34)

Se por um lado a estrofação é uma forma de dividir os versos, levantando fronteiras em um texto poético, por outro busca-se uma forma fluida por meio dos enjambements, do fluxo expressivo, dos versos longos, das iniciais minúsculas, da profusão de diferentes vozes pelas referências intertextuais. É assim que essas primeiras estrofes transitam das fronteiras astrológicas (dia e noite), substanciais (água e terra) e cromáticas (azul e lilás) para pensar as fronteiras geopolíticas do passado colonial. É assim que o imaginário orientalista (Cf. Said, 2007) é evocado como forma de definir o espaço alheio, seja por meio dos textos ficcionais, como Coração das trevas (1889), de Joseph Conrad, seja por meio de acordos políticos, como o Tratado de Tordesilhas (1494) ou a Conferência de Berlim (1884-5), ou ainda por meio das pretensões lusitanas sobre o domínio de territórios africanos no Mapa Cor-de-Rosa (1890).

E se a cultura orientalista do colonialismo, com caneta, estilete, bisel, bissetriz segmentou, definiu, catalogou e classificou territórios, culturas, línguas e povos, o sujeito- 
-lírico utiliza o espaço de seu poema para escrevê-lo a partir do interstício. Assume-se então o espaço intervalar entre literatura e realidade, entre ficção e política, entre poesia e narrativa, entre versos e estrofes, entre o território colonial imposto e o território assumido pelos sujeitos que herdam a sociedade colonial.

Ao evocar essa condição intersticial para ressaltar as fronteiras que não possui, Ana Mafalda Leite insere-se em uma vertente da poesia moçambicana que pode ser destacada a partir de figuras como Rui Knopfli, Luís Carlos Patraquim e Eduardo White. Se nomes como José Craveirinha e Noémia de Sousa foram responsáveis por uma poesia de combate, que prezava pela territorialidade em uma poética fundada no espaço moçambicano e africano, tendo o corpo negro como materialidade da resistência ao colonialismo, os poetas ressaltados destacaram-se pela ambivalência entre os elementos culturais portugueses e moçambicanos.

Dessa forma, em oposição à relação telúrica que fixa o sujeito identitariamente à terra, pode-se pensar a partir de Knopfli, mas também em Patraquim e White, uma tradição poética que preza pelos fluxos, pelos deslocamentos, pela diferença ${ }^{4}$. Não ao acaso, em todos esses poetas o Índico e o Oriente são símbolos frequentemente utilizados para marcar o lugar de uma poesia que preza pela modernidade, pela sinestesia e pelas referências metapoéticas, evocando diferentes tradições culturais e literárias, também rasurando as fronteiras pelo transitar.

A poesia de Ana Mafalda Leite se insere nessa poética do deslocamento simbolizada pelas correntes do Índico em oposição à fixidez da terra, alternando referências à poesia e à cultura moçambicana, mas também a uma modernidade literária para além do nacional. Em "Poemas do Nyau, a grande dança", que compõe Outras fronteiras, a máscara Dzwirombo afirma: "somos os misturados descoincidentes zoomórficos / criaturas e criadores" (LEITE, 2017, p. 30). Assim como a máscara, a poesia reivindica o reverso da identidade, reivindica ser misturada e descoincidente, ser moçambicana e portuguesa, ser oriental e ocidental, buscar a modernidade da poética de um Patraquim, mas também trazer à tona a tradição da voz de um Craveirinha.

No posfácio da edição brasileira de Outras fronteiras, Carmen Tindó Secco (LEITE, 2017, p. 76) assinala: "Entre Ocidente e Oriente, Moçambique só é possível pelo cruzamento de 'acasos conjurados', voz do passado rente ao Índico e às diversas etnias africanas que habitam a terra moçambicana”. É justamente esse cruzamento de acasos conjurados que permite que os poemas rasurem as fronteiras erigidas na colonização, sejam elas espaciais, identitárias ou poéticas. Se o espaço é de fato o confronto de narrativas que o significam, como defende Massey (2008), Ana Mafalda expande em seus versos o nosso mundo, assinalando a presença das fronteiras coloniais para rasurá-las, trazendo à tona os discursos do passado para que compreendamos o presente.

No poema "Os itinerários sem mapas", o sujeito lírico destaca seu desejo de cartografar: "registo tudo aquilo que me permita vir a construir um mapa nestas páginas que mal consigo ver" (LEITE, 2017, p. 48). No entanto, ao final do texto, destaca a impossibilidade dessa cartografia: "Intuo que não chegarei ao fim desta jornada / os mapas irão perder-se comigo algures por estes descaminhos / Procuro em vão desenhar os itinerários de

4 Em seu trabalho como pesquisadora, Ana Mafalda Leite (2012) assinala a importância dos elementos, como a terra e o fogo, a água e o ar, na escrita da nação na literatura moçambicana. A partir de nomes como Patraquim, White, de Lemos e Mia Couto, chama atenção para os dois últimos elementos. 
ouro entre oriente e ocidente" (LEITE, 2017, p. 49). E se essa perspectiva intersticial não cabe nos mapas, só é possível caber na ausência de fronteiras da poesia - não de qualquer poesia, mas de uma poesia que se anuncia pelo deslocamento, que se vincula aos fluxos culturais de uma poética do Índico.

E assim, para além das fronteiras que não temos, mas que nos foram impostas desde cinco séculos, buscamos no presente ouvir a poética voz que se anuncia "do outro lado do tempo, num outro mar e num outro continente" (LEITE, 2017, p. 73), como destacado em "Caminhos no deserto", poema que encerra Outras fronteiras mas não se impõe como fronteira, abrindo-nos a possibilidade de navegar.

\section{Referências}

LEITE, Ana Mafalda. Outras fronteiras: fragmentos de narrativas. São Paulo: Kapulana, 2017.

. Poéticas do imaginário elemental na poesia moçambicana - entre mar... e céu. In.: __ Oralidades \& escritas pós-coloniais: estudos sobre literaturas africanas. Rio de Janeiro: EdUERJ, 2012. p. 297-305.

MASSEY, Doreen. Pelo espaço: uma nova política da espacialidade. Trad. Hilda Maciel; Rogério Haesbaert. Rio de Janeiro: Bertrand Brasil, 2008.

SAID, Edward. Orientalismo: o Oriente como invenção do Ocidente. Trad. Rosaura Eichenberg. São Paulo: Companhia das Letras, 2007.

SECCO, Carmen Lucia Tindó. Outras fronteiras: o brilho dos pirilampos e os fragmentos da memória. In.: LEITE, Ana Mafalda. Outras fronteiras: fragmentos de narrativas. São Paulo: Kapulana, 2017. p. 74-76. 